This item was submitted to Loughborough's Research Repository by the author.

Items in Figshare are protected by copyright, with all rights reserved, unless otherwise indicated.

\title{
Ergonomics analysis in a virtual environment
}

PLEASE CITE THE PUBLISHED VERSION

http://dx.doi.org/10.1504/IJMR.2007.014645

\section{PUBLISHER}

() Inderscience

\section{VERSION}

AM (Accepted Manuscript)

\section{PUBLISHER STATEMENT}

This work is made available according to the conditions of the Creative Commons Attribution-NonCommercialNoDerivatives 4.0 International (CC BY-NC-ND 4.0) licence. Full details of this licence are available at: https://creativecommons.org/licenses/by-nc-nd/4.0/

\section{LICENCE}

CC BY-NC-ND 4.0

\section{REPOSITORY RECORD}

Backstrand, Gunnar, Dan Hogberg, Leo J. De Vin, Keith Case, and Paul Piamonte. 2019. "Ergonomics Analysis in a Virtual Environment”. figshare. https://hdl.handle.net/2134/26588. 


\title{
Ergonomics analysis in a virtual environment
}

\section{Gunnar Bäckstrand*}

School of Technology and Society

University of Skövde

Box 408, SE-541 28, Skövde, Sweden

and

Mechanical and Manufacturing Engineering

Loughborough University

Loughborough, Leicestershire, LE11 3TU, UK

and

Volvo Powertrain Sweden

SE-541 87, Skövde, Sweden

E-mail: Gunnar.backstrand@volvo.com

*Corresponding author

\section{Dan Högberg and Leo J. De Vin}

School of Technology and Society

University of Skövde

Box 408, SE-541 28, Skövde, Sweden

\section{Keith Case}

School of Technology and Society

University of Skövde

Box 408, SE-541 28, Skövde, Sweden

and

Mechanical and Manufacturing Engineering

Loughborough University

Loughborough, Leicestershire, LE11 3TU, UK

\section{Paul Piamonte}

Volvo Technology Corporation

SE-405 08, Göteborg, Sweden

\begin{abstract}
Simulation can support the design of an ergonomic workplace by enabling early assessment of ergonomic conditions in a virtual environment. An important feature is the possibility to study alternative solutions or the effect of improvements from an ergonomics perspective. To be able to conduct an efficient and reliable evaluation in a virtual environment, an objective analysis method is essential. Such an analysis method should be integrated in the simulation software, and support a company's everyday ergonomics work process. In order to gain from existing ergonomics knowledge within a company, the possibility to implement such wisdom in the current simulation software becomes important.
\end{abstract}



This paper presents an implementation work done with the purpose of integrating an established ergonomics work process into a virtual environment. It describes the benefits of an ergonomics work process where simulation and evaluation at early stages of a design process are key factors. The paper will also describe the integration process, i.e., the technical issues as well as the change in work methods.

Keywords: simulation; ergonomics; workplace design.

Reference to this paper should be made as follows: Bäckstrand, G., Högberg, D., De Vin, L.J., Case, K. and Piamonte, P. (2007) 'Ergonomics analysis in a virtual environment', Int. J. Manufacturing Research, Vol. 2, No. 2, pp.198-208.

Biographical notes: Gunnar Bäckstrand is a $\mathrm{PhD}$ student at Loughborough University, UK. He is employed by Volvo Powertrain, Sweden as a research student. He received his BSc in Automation Engineering from the University of Skövde in 2002 and his MSc in Automation from the University of Skövde in 2003. His research interests include human behaviour, information systems and HMI.

Dan Högberg is an Associate Professor at the School of Technology and Society at the University of Skövde. He received his BSc in Product Design Engineering from the University of Skövde in 1998, his MSc in Engineering Design from Loughborough University, UK in 1999 and his PhD from Loughborough University in 2005. He teaches engineering design and ergonomics at the University of Skövde. His research interests include computer-based methods and support systems for designers and engineers to consider human-related issues in virtual design processes, e.g., the integration of digital human modelling. He is a member of the Virtual Ergonomics Centre (VEC) (www.vec.se).

Leo J. De Vin is a Full Professor and the Head of the Centre for Intelligent Automation at the University of Skövde in Sweden. He received his PhD in Computer Aided Process Planning from The University of Twente in the Netherlands, and later worked as a Researcher Officer for The University of Ulster at Jordanstown (UK) before joining the University of Skövde, initially as a Visiting Lecturer in Integrated Product Development. Current research interests include virtual manufacturing, information fusion, and human factors in engineering. De Vin has (co-)authored around 100 scientific articles as well as a number of technical reports.

Keith Case is a Professor of Computer Aided Engineering in Mechanical and Manufacturing Engineering at Loughborough University and is a Chartered Engineer, a Fellow of the Ergonomics Society and a Fellow of the British Computer Society. He leads the Product Realisation Technologies Research Group and is a Director of the Centre of Excellence in Customised Assembly. In 1994 he received the Ergonomics Society Otto Edholm Award in recognition of his significant contribution to the development and application of ergonomics, primarily in the area of virtual human modelling. His previous research was in the fields of manufacturing engineering and design, human modelling and manufacturing ergonomics.

Paul Piamonte is the Group Manager for the Human Factors Group under the Department of Humans, Systems and Structures of Volvo Technology Corp. He has BSc (Biology 1983) and MD (Doctor of Medicine 1987) degrees from the Philippines; and MSc (1995) and PhD (2000) degrees in Industrial Ergonomics 
from Luleå University of Technology, Sweden. He manages different projects in the areas of product and production ergonomics for different Volvo companies and their clients. His group is also involved in several national (Swedish) and EU-sponsored projects in the same areas.

\section{Introduction}

Most of today's ergonomics simulation tools (a.k.a. computer manikin tools, human modelling or human simulation systems) have different types of ergonomics analysis methods integrated in the software to support objectivity when evaluating human-product interaction design proposals. Commonly integrated evaluation methods are NIOSH (Waters et al., 1993), OWAS (Karhu et al., 1977) and RULA (McAtamney and Corlett, 1993). These and similar methods all have strengths and weaknesses. An example of weaknesses is the lack of support for national health regulations as well as company-specific regulations. The identification of this limitation, i.e., that there is a gap between the company-specific strain assessment guidelines and analysis methodology, on the one hand, and the analysis methods provided within the utilised simulation software, on the other, was the origin of the work presented in this paper. The idea was that the combination of the advantages offered by modern simulation technology with established company-specific ergonomics knowledge would result in an effective and efficient solution that would be recognisable and accepted among the people involved in the workplace design process, e.g., production engineers, ergonomists and managers.

\section{Advancing the industrial development process}

The product realisation process (Figure 1) in modern industry is typically very complex, with a lot of issues to consider for finding the best balance among the full range of valueadding characteristics, and the process is typically constrained by tough time and cost restrictions. As a result, marketing, product and manufacturing development activities must be performed efficiently and the money put where it is most beneficial.

Figure 1 A typical development process

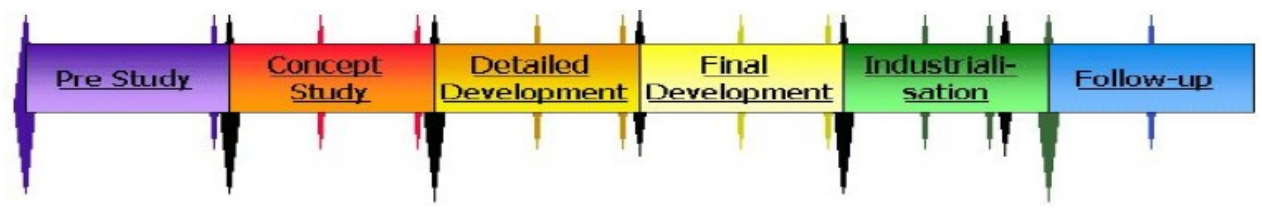

In the product realisation process work, two things incur large costs. One is the product realisation process itself, strongly influenced by the Time-To-Market span (Figure 2). Another major expenditure is the cost of building physical mock-ups. In addition, the quality of the outcome of the realisation process, i.e., the product, naturally has a major effect on a project's economic return. Common approaches to increase the efficiency of the product realisation process are to carry out more or less parallel activities (Figure 2), 
to work in cross-functional teams, and to employ methods that support Right-First-Time outcomes. The costs and effort required for design alterations are moderate at early development stages compared to design changes later in the process, which are typically expensive, time consuming and complicated to handle (Ullman, 2003).

Figure 2 Time-To-Market with partially overlapping development processes

\section{Time-To-Market}

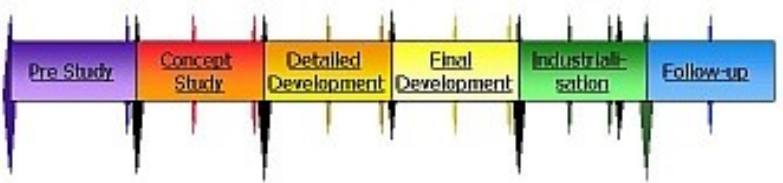

Marketing Development

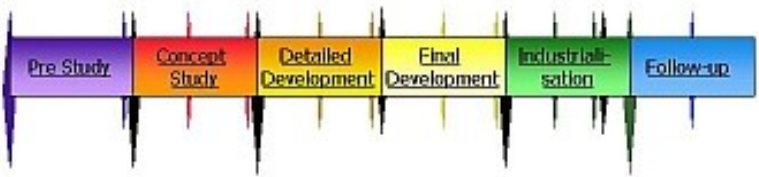

Product Development

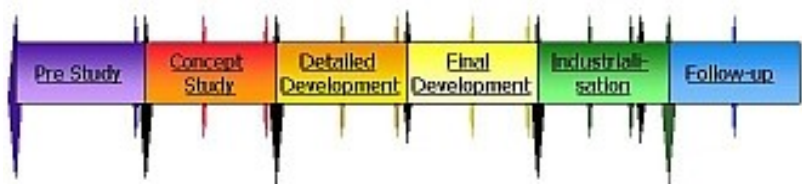

Manufacturing Development

As a result, simulation is intensively used in industry to uphold profitability and competitiveness by reducing development time and cost and by promoting product quality. This means that expensive, inflexible and time-consuming physical mock-ups are only built towards the end of the development process. Thus, the ability to evaluate a design from an ergonomics point of view in a virtual environment has become vital to reduce the risks of time-consuming and expensive iterations, or products that do not meet the full ergonomics specification (Porter et al., 1995).

\section{Company-tailored approach to ergonomics simulation}

The company where this work was initially carried out (Bäckstrand and Jonasson, 2001) has an established company-specific ergonomics analysis methodology, known as BUMS (basically a Swedish abbreviation for Saab’s Ergonomics Strain Assessment Guidelines). This method has been developed over many years and is acknowledged in the organisation by engineers, ergonomists and managers as the method to use for analysing ergonomic conditions related to manufacturing. This is one of the reasons why Volvo Powertrain Sweden, Skövde took the decision in 2004 to adopt BUMS as one of the methods for workplace design evaluation. 
The outcome from a BUMS analysis is typically used as a decision base when identifying which workplaces are acceptable (green) or needs to be under consideration (yellow) or must be rectified (red). The method contains ergonomics experiences developed over the years, as well as complies with national (Swedish in this case) health regulations. This knowledge would be lost, or very hard to utilise, if the integrated 'standard' evaluation (such as NIOSH, RULA, etc.) methods would be the alternative to use when performing ergonomics analyses in a virtual environment.

Hence, the objective of the project was to integrate BUMS within the utilised simulation tool (IGRIP in this case) in order to benefit from both existing ergonomics experiences and modern simulation technology, and thereby end up with a solution that would be tailored to the company's needs and procedures (Bäckstrand and Jonasson, 2001).

In general, when developing any support system to be employed in a company's product realisation process (in the context of this paper, the workplace can be seen as the product), it is important that the support system (in this case, a computer-aided tool for ergonomics analysis) is tailored to the company's needs and procedures. In a similar example to the BUMS implementation, one of the lessons learned in research on Computer-Aided Process Planning (CAPP) in the 1990s was that CAPP systems needed to be adaptable to company-specific procedures and technology. The CAPP system PART, for instance, offered the possibility to specify company-specific process-planning scenarios and company-specific rules for machining (Van Houten, 1991), and this was a prerequisite for its further development from academic prototype to commercial product (as part of Tecnomatix’ eMPower solutions).

\subsection{Process benefits}

The BUMS implementation in the simulation tool enables the ergonomics evaluation to be moved from analysing the existing workplace in the 'Final Development' or the 'Follow-up' phase up to the 'Pre Study' phase (Figure 1), where the evaluation is performed on a virtual workplace design proposal. This makes it possible to perform initial ergonomics evaluations much earlier; depending on the nature of the project this may be up to three years earlier.

Evaluation of a design at the early stages is beneficial, e.g., to identify design defects early on and to support strong arguments to management for considering ergonomics deficiencies. However, in many cases, the evaluation of a physical prototype is unbeatable in establishing ergonomic conditions owing to the complexity of influencing issues, e.g., holistic implications and user diversity - making it difficult to perform realistic simulations in virtual environments. A sensible view is that simulation tools support the development of more correct assumptions about the eventual characteristics of the product-to-be (the workplace in this case), with the objective that first prototypes will require fewer modifications than would be the case without the aid of the tools (De Vin and Sohlenius, 2006; Högberg, 2005). Thus, there are obvious benefits with simulation; when the production equipment is in place on the shop floor it will be much more difficult to make changes. 


\subsection{Ergonomics simulation work process}

The work process for ergonomics simulation (Figure 3) is divided into three major phases:

1 preparation of the virtual work environment

2 analysis, divided into Run simulation and Run analysis

3 evaluation of results.

Figure 3 Ergonomics simulation work process

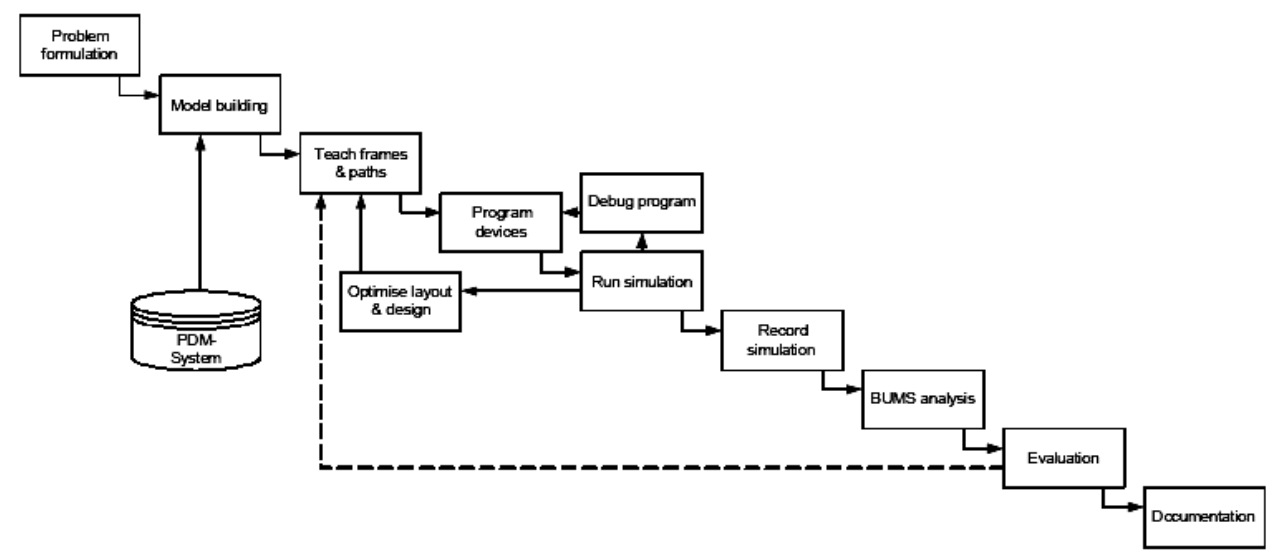

\subsubsection{Preparation of the virtual work environment}

This phase consists of a number of steps, stretching from 'Problem formulation' to 'Record simulation' (Figure 3). The overall objective is basically to build the virtual environment, to define users and to define the tasks to be performed.

This phase is controlled by a number of steering documents and regulations, e.g., related to ergonomics, layout and logistics. A conceptual workplace design model is created, based on these regulations, together with:

- $\quad$ Product - engine, car parts, etc.

- Process - The process controls how a task should be performed but also how it might be performed. For instance, available lifting aids may not always be used in practice.

- Resources - computer manikins, lifting aids, material-handling equipment, assembly tools, etc.

This phase is typically relatively time consuming, depending on the infrastructure and complexity of the work-environment-to-be. A figure of $45 \%$ or more of total simulation time is reported as being common (Blomé et al., 2003).

\subsubsection{Analysis}

In the analysis phase, an Excel sheet is used. The method used is more or less the same as for analysis on physical objects. The Excel sheet is connected to the simulation software, which makes it possible to export analysis results from the virtual environment 
in real time to the sheet. The simulation engineer conducts a number of analyses with different manikins (typically, two male and two female), different lifting aids and so on. The main objective for this phase is to generate analysis results in an efficient manner so that as much time as possible can be spent on the actual evaluation work in later stages. A current drawback of this work process is the limited possibility to simulate and analyse 'families' of manikins. Simulation with a selection of manikins would create a much better and more detailed understanding of how the anthropometric diversity of the users and the ergonomic conditions are related to each other (Högberg, 2005).

\subsubsection{Evaluation of results}

The evaluation of the analysis results is done in a workshop with participants from production preparation, i.e., Ergonomics Experts (EEs) and Simulation Engineers (SEs), and from the production itself, i.e., the workplace users. This workshop contains:

- Validation of the model - evaluation conducted by production preparation personnel and EE. This validation is done with an agreed Target of Acceptance (De Vin and Sohlenius, 2006) in mind. The participants act as subject matter specialists who contribute to the validation process from within their respective areas of expertise.

- Simulation walkthrough - run simulation, change postures, etc.

- BUMS analysis - from the problem definition, the SE has prepared a list of different areas that should be of special interest in advance. A BUMS analysis is conducted; each analysis takes approximately one minute. The result is discussed and snapshots are produced showing the analysis object.

- Discussions and decisions - the objective is to generate a suggestion/solution on how to use a possibility or how to solve a problem in the best possible way.

\section{Implementation and technical issues}

Some software programs have the capability of building software applications within the specific software via an Application Programming Interface (API). The API works as an interface between the software developer and the software and the main purpose is to access functions within the software. This access can be via other programs, e.g., between a CAD program and a simulation program, but it can also be used to create macros within a specific software. In this case, the BUMS application uses APIs, provided within IGRIP and MS Excel to create macros that in the next step can be used to analyse the manikin in the virtual environment and to view the results from the analysis.

The APIs in IGRIP make it possible to read manikin joint values, create dialog boxes, etc. The joint values form the most important part of the analysis and depending on the manikin used, it is possible to access approximately 100 joint values. These values are used to calculate where in space different manikin body parts are located. These locations are compared with the boundaries stated in BUMS. This is done by the application and only the result is shown to the user in the virtual environment. The result is visualised as colour changes on manikin body parts, in a pop-up window, and in the Excel sheet as coloured boxes (see Figure 4). 
Figure 5 shows the program structure and how the different programs interact with each other. When the user 'pushes a button' on the button menu (illustrated in Figure 6) in the virtual environment, a program starts executing and calls for a function or procedure. These functions/procedures include APIs, called Graphical Simulation Language (GSL)-Macro. The GSL-Macro executes different tasks, e.g., it reads manikin joint values and returns these values to the procedure. Depending on the purpose, the function/procedure executes a task, e.g., shows a pop-up dialog window.

Figure 4 BUMS analysis results shown as changed colours in the Excel sheet and on body parts of the manikin

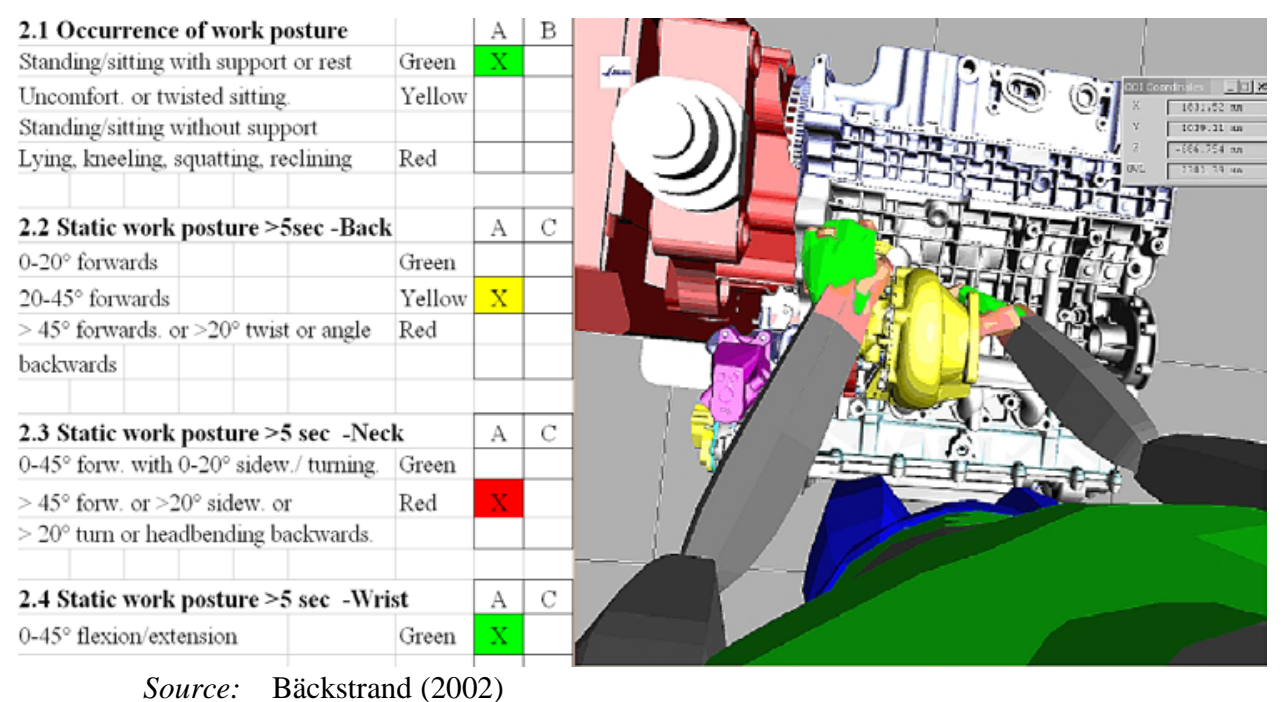

Figure 5 Program structure for the BUMS application in the virtual environment

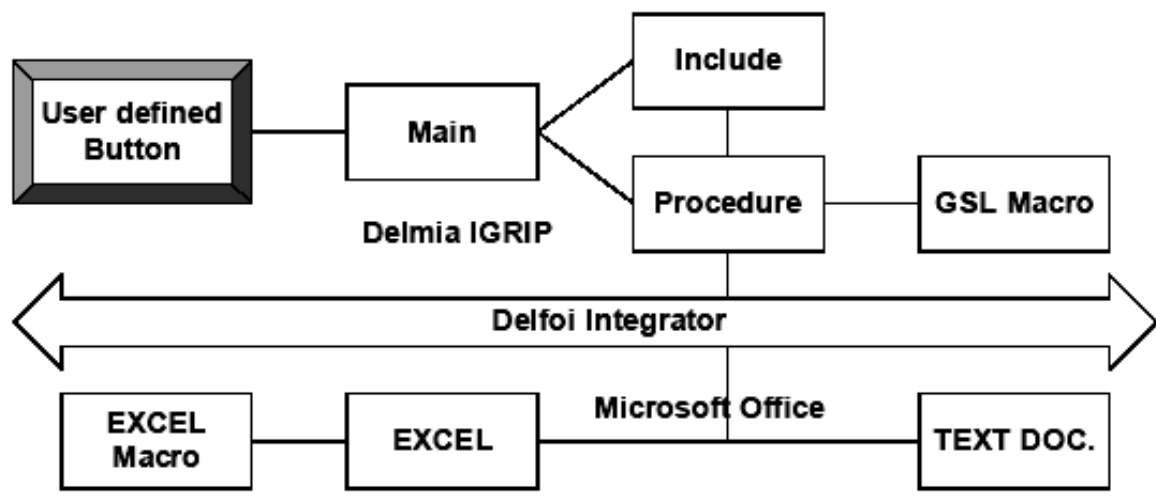

The result, a set of analysis values, is exported to the BUMS Excel sheet via the 'Delfoi Integrator' interface. When a procedure receives a return value from a GSL-Macro, it compares this value with the boundaries or rules that are stated in BUMS. An example can be a return value for head bending of $46^{\circ}$. According to BUMS, this value indicates that the maximum angle for head bending is exceeded and that this will create an ergonomic problem connected to that (assembly) task. As mentioned earlier in this paper, 
the result from the analysis is presented by using the colour green, yellow or red. In this example, the angle would generate a red-coloured neck and a red-coloured cell in the Excel sheet shown in Figure 4. This red cell is create by a 'Visual Basic for Application', VBA-Macro. The execution of the VBA-Macro is controlled from the BUMS application integrated in the simulation software. The application sends a control parameter from the functions/procedure via Delfoi Integrator to the Excel sheet. The parameter starts the execution of the proper VBA-Macro, e.g., the macro that colours the cell green, yellow or red. When this is done, the Excel sheet is ready to receive new parameters for macro execution. This process continues until the analysis is done minutely and includes 11 different analysis stages.

The BUMS method can be readily adapted to accommodate different ergonomic standards by defining specific rules and boundary values. These can be company specific or task specific, for instance a head turn that is perfectly acceptable for an assembly workstation may not be acceptable for a driver's environment. Figure 6 shows a button menu with two sets of rules (BUMS Design and BUMS Production).

Figure 6 Graphical user interface for BUMS integrated in the simulation tool

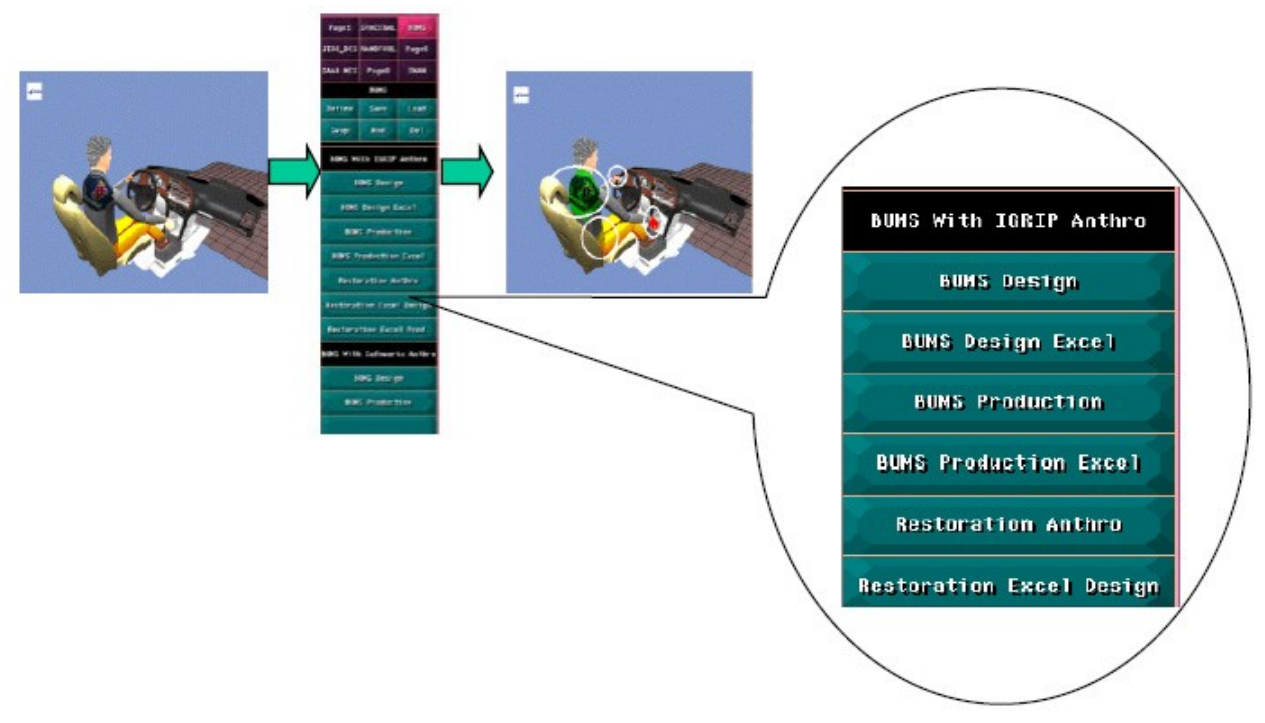

Source: Bäckstrand (2002)

\section{Conclusion and future work}

\subsection{Conclusion}

Companies can benefit from early ergonomics analysis, as it reduces the need for physical mock-ups and expensive design changes at late stages in the product development process. BUMS facilitates early ergonomics analysis with the use of simulation. It allows non-ergonomists such as simulation engineers to obtain an understanding of ergonomic consequences of a proposed design and allows them to identify issues of particular interest that can be studied in more detail with help from ergonomics experts and prospective users. 
Whilst BUMS was initially developed at Saab, it was later adopted by Volvo Powertrain. This was made possible owing to the structure of BUMS; it is relatively easy to tailor the ergonomic rules in BUMS to company-specific rules.

When implementing a system like BUMS, it is important to integrate it in the company's work process in order to benefit from it as much as possible. Whilst ergonomic simulation and analysis have their own value, the real benefits emerge during the evaluation of results (which typically involves a variety of experts and stakeholders).

\subsection{Future work}

It is not difficult to see how BUMS can improve a workplace design. However, what is lacking is a possibility to do cost/benefit calculations connected to results from an ergonomics analysis. It would be very useful if ergonomics improvements could be linked quantitatively to economic benefits. This would make it possible to compare different workplace designs not only from an ergonomic but also from an economic point of view. Although this is not easy owing to the vast amount of parameters, work is in progress to find an economy model that can be used together with ergonomics analysis tools such as BUMS (Bäckstrand et al., 2005).

Like many other simulation tools, BUMS currently lacks the capability to run a simulation with a selection of manikins from a manikin family automatically. At present, this is a manual task, which means that manikins have to be picked manually and a separate simulation has to be carried out with each manikin. The automation of this process would be a major improvement that will be considered for future versions of BUMS.

While this paper covers considerations of physical ergonomics, the consideration of cognitive ergonomics is just as important. In a modern manufacturing environment, appropriate presentation of data and information is becoming increasingly crucial. Therefore, it is very important to be able to evaluate information need and information flow at early stages of the design process; where, when and how should data/information be presented within a workplace? Ergonomics simulation in combination with discrete event simulation appears to have the potential to be useful as a future tool for the evaluation of how to present information.

\section{References}

Bäckstrand, G. (2002) 'Virtual reality, an assembly planning aid in a manufacturing environment', Master thesis [in Swedish], University of Skövde, Sweden.

Bäckstrand, G. and Jonasson, H. (2001) 'Implementation of Saab’s ergonomics strain assessment guidelines to a virtual environment', Bachelor thesis [in Swedish], Department of Engineering Science, University of Skövde, Sweden.

Bäckstrand, G., Möller, S., Högberg, D., De Vin, L.J., Sundin, A. and Case, K. (2005) 'A roadmap towards cost calculation methods connected to ergonomics analysis and simulation', 37th Ann. Conf. of the Nordic Ergonomics Society (NES), Oslo, Norway, pp.312-316.

Blomé, M., Dukic, T., Hanson, L. and Högberg, D. (2003) Simulation of Human-vehicle Interaction in Vehicle Design at Saab Automobile: Present and Future, Society of Automotive Engineers, SAE Technical Paper 2003-01-2129.

De Vin, L.J. and Sohlenius, G. (2006) 'The role of simulation in innovative industrial processes', IMC-23, University of Ulster, Ireland, pp.527-534. 
Högberg, D. (2005) 'Ergonomics integration and user diversity in product design’, Doctoral thesis, Loughborough University, United Kingdom.

Karhu, O., Kansi, P. and Kuorinka, I. (1977) 'Correcting working postures in industry - practical methods for analysis’, Applied Ergonomics, Vol. 8, pp.199-201.

McAtamney, L. and Corlett, E.N. (1993) 'RULA - a survey method for the investigation of workrelated upper limb disorders', Applied Ergonomics, Vol. 24, pp.91-99.

Porter, J.M., Freer, M.T., Case, K. and Bonney, M.C. (1995) 'Computer aided ergonomics and workspace design', in D.R. Wilson and E.N. Corlett (Eds.) Evaluation of Human Work: A Practical Ergonomics Methodology, London: Taylor \& Francis, pp.574-620.

Ullman, D.G. (2003) The Mechanical Design Process, New York: McGraw-Hill.

Van Houten, F.J.A.M. (1991) 'PART: a computer aided process planning system', Doctoral thesis, University of Twente, the Netherlands.

Waters, T.R., Putzanderson, V., Garg, A. and Fine, L.J. (1993) 'Revised NIOSH equation for the design and evaluation of manual lifting tasks', Ergonomics, Vol. 36, pp.749-776. 